\title{
Correction to: 5-Aminolevulinic acid (ALA) biosynthetic and metabolic pathways and its role in higher plants: a review
}

\author{
Yue $\mathrm{Wu}^{1} \cdot$ Weibiao Liao ${ }^{1} \cdot$ Mohammed Mujitaba Dawuda ${ }^{1,2} \cdot$ Linli Hu$^{1} \cdot$ Jihua Yu $^{1}$ (1)
}

Published online: 2 May 2019

(c) The Author(s) 2019

\section{Correction to: Plant Growth Regulation (2019) 87:357-374 https://doi.org/10.1007/s10725-018-0463-8}

The article listed above was initially published with incorrect copyright information. Upon publication of this Correction, the copyright of this article changed to "The Author(s)". The original article has been corrected.

Publisher's Note Springer Nature remains neutral with regard to jurisdictional claims in published maps and institutional affiliations.

The original article can be found online at https://doi.org/10.1007/ s10725-018-0463-8.

Jihua Yu

yujihuagg@163.com

1 College of Horticulture, Gansu Agricultural University,

No. 1 Yinmen Village, Anning District, Lanzhou 730070,

People's Republic of China

2 Department of Horticulture, FoA, University for Development Studies, P. O. Box TL 1882, Tamale, Ghana 